\title{
Effect of number of trials, interstimulus interval, and dishabituation during CS habituation on subsequent conditioning in a CER paradigm*
}

\author{
ALMA E. LANTZ \\ Denver Research Institute, University of Denver, Denver, Colorado 80210
}

\begin{abstract}
Three experiments were conducted to investigate the influence of variables during habituation of a CS on a subsequent conditioning to that $\mathrm{CS}$ in a conditioned emotional response paradigm. Experiment I varied the number of habituation trials received before conditioning, and it was found that additional habituation trials resulted in a further attenuation of conditioning. Experiment II varied the interstimulus interval of the habituating stimulus, and it was found that the longer intervals produced the greater attenuation in conditioning. Experiment III examined the effect of interpolating another stimulus between habituation and conditioning (dishabituation), and it was found that the dishabituating stimulus augmented subsequent conditioning. It was concluded that manipulations during habituation training that produce the greatest decrement in response to a stimulus, when assessed under equivalent conditions for all animals, have the greatest attenuating effect on subsequent conditioning to that stimulus.
\end{abstract}

Preexposure to a to-be-conditioned stimulus results in a decrement in conditioning performance when compared with a nonpreexposed group. This effect of attenuation of conditioning following CS habituation has been demonstrated in classical Pavlovian conditioning (Lubow, 1965; Lubow \& Moore, 1959) and in conditioned emotional response (CER) paradigms (Carlton \& Vogel, 1967; Lubow \& Siebert, 1969; Siegel, 1969).

The decrement of conditioning following stimulus preexposure has been labeled "latent inhibition" (Lubow, 1965; Lubow \& Moore, 1959), al though several recent investigators have concluded that such preexposure results in a decrement of attention (Reiss \& Wagner, 1972) or a reduction in stimulus saliency (Rescorla, 1971) rather than conditioned inhibition. However, the first phase of all of the experimental paradigms that produce a decrement in conditioning is a habituation phase. That is, Ss receive habituation training to the CS prior to conditioning. Since the "parameters" influencing rate and/or asymptotic level of habituation have been widely investigated (e.g., Thompson \& Spencer, 1966), the purpose of this study was to evaluate whether or not the parameters that have been found to be effective in habituation paradigms will also be effective in latent inhibition paradigms. Consequently, three experiments were conducted in which stimulus variables influencing habituation

\footnotetext{
*These data were based on a dissertation submitted to the Department of Psychology, Rutgers, The State University, in partial fulfillment of the $\mathrm{PhD}$ degree under the direction of Peter L. Cariton. The author also wishes to thank Russell Leaf and Joseph Halpern for their assistance in conducting the research. The research was supported in part by Grant NH-08585 to Peter Carlton. Requests for reprints should be sent to A. E. Lantz. Denver Research Institute, Industrial Economics Division, University of Denver. Denver. Colorado 80210
}

(number of trials, interstimulus interval, and dishabituation) were manipulated during stimulus preexposure prior to conditioning.

\section{EXPERIMENT I}

Thompson and Spencer (1966) and Groves and Thompson (1969) concluded, from a review of the literature and from their own research, that habituation is typically a negatively accelerated function of the number of habituation trials. Lubow (1965) demonstrated that an increase in the number of CS habituation trials prior to the classical conditioning of a leg flexion response in sheep and goats resulted in additional attenuation of subsequent conditioning. The present experiment was designed as an attempt to replicate the Lubow findings in a CER paradigm.

\section{Method}

\section{Subjects}

The Ss were 40 male albino rats obtained from Simonson Laboratories. All Ss were 60 to 70 days old and weighed between 280 and $300 \mathrm{~g}$ at the beginning of the experiment.

\section{Apparatus}

All Ss were placed in a transparent Plexiglas chamber with a grid floor; the chamber measured $81 / 2 \times 31 / 2 \times 7$ in. The Plexiglas chamber was housed in a larger chamber made of plywood and lined with acoustical tile. The inside dimensions were $14 \times 14 \times$ 13 in. The chamber was illuminated by a $7-W$ white light. The auditory signal was a $1.000-\mathrm{Hz}$ tone, as calibrated by a Tectronix 545 oscilloscope. The tone was generated by an RCA Model WA44C audio generator, and was amplified by a Lafayette Model 1421 audio amplifier; it was delivered to Ss through $23 / 4$-in. Archer 5-W, 8-ohm conical speakers. The decibels of the tone were calibrated by a General Radio Model 1565A sound pressure level meter. The ambient noise level was approximately 26-32 $\mathrm{dB}$ inside the chamber. 


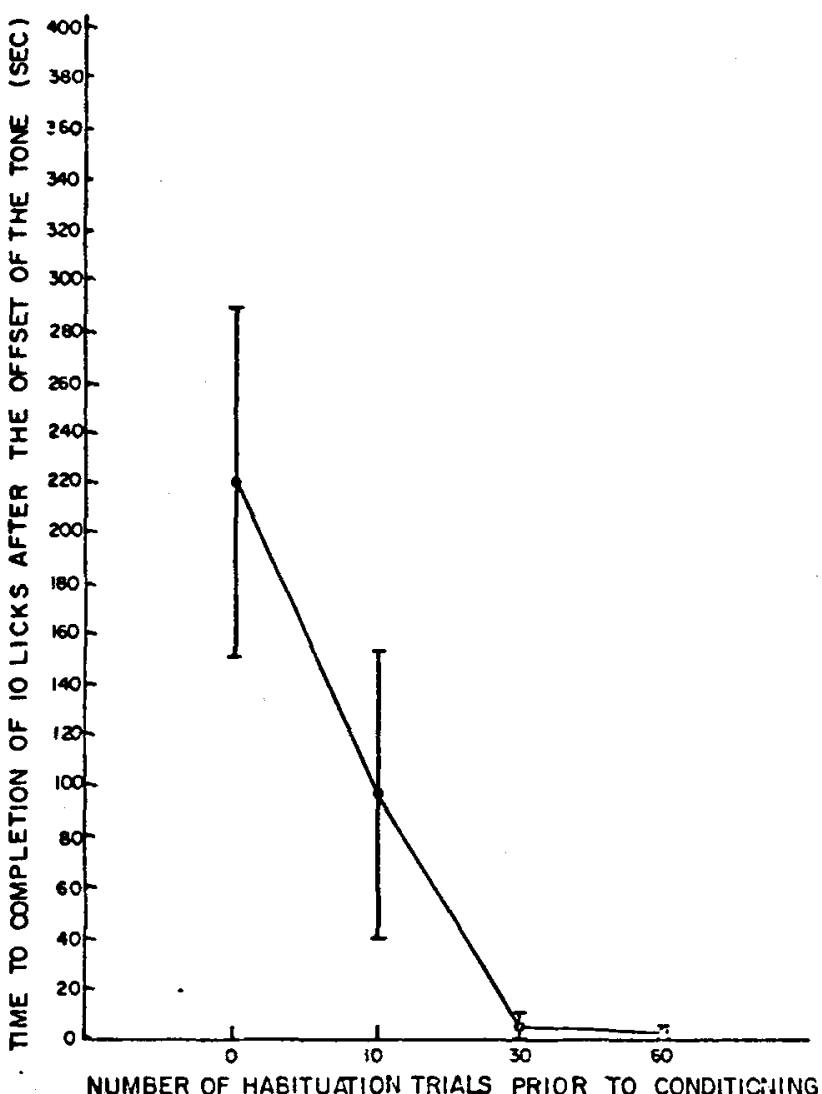

Fig. 1. Mean time to complete 10 licks after the offset of the tone by the number of CS habituation trials.

Shock could be delivered to $S$ through the grid floor of the chamber. The shock was generated by a Lafayette Model 5226 shocker at 500 ac shock voltage, with a $100 \mathrm{~K}$ external resistor, and was delivered via a Lafayette A620 grid scrambler. Control of the duration of the stimulus, the duration of the shock, and the interstimulus interval was provided by two Model $110 \mathrm{C}$ and three Model $100 \mathrm{C}$ Hunter timers. Response times were measured with a Hunter Model 1522 digital display timer/counter and a Lafayette 54015 digital stop clock; the drinkometer was a Grason-Stadler E4690A-1. All rats were maintained on ad lib food and water, except as noted below.

\section{Procedure}

There were four groups of $10 \mathrm{Ss}$ each. All groups received different experimental treatments on Day 1 during the habituation/conditioning session but identical treatments during the testing session on the following day. During the habituation/conditioning session, one group received 10 habituation trials (Group 10), each trial consisting of the presentation of a $60-\mathrm{dB} 10-\mathrm{sec}$ tone followed by a $30-\mathrm{sec}$ interstimulus interval. The final tone was paired with shock; $8 \mathrm{sec}$ after the onset of the 10th tone, the shock came on for $2 \mathrm{sec}$, such that the offset of the tone and shock coincided. Another group received 30 habituation trials (Group 30), and a third group received 60 trials (Group 60 ) of the same tone at a 30-sec ISI. The final tone for both groups was paired with shock in an identical manner to that for Group 10. The remaining group served as a control group, and remained in the experimental chamber in the absence of auditory stimulation for $40 \mathrm{~min}$; following the 40 -min interval, a tone-shock pairing identical to that received by the other groups was experienced (Group 0). All Ss were returned to their home cages, from which the water bottle had been removed.

Twenty-four hours later, the testing session was given. Each $\mathrm{S}$ was placed in a chamber identical to that used in the habituation/conditioning session, except that a drinking tube was now present. After $S$ completed 100 licks, the tone. identical to that used during conditioning, was initiated. The time from the offset of the tone until the completion of 10 licks was used as a response measure to indicate the amount of suppression occasioned by the tone. All $S s$ were removed from the experimental chamber if they had not completed 10 licks within $600 \mathrm{sec}$ after the offset of the tone, and their response time was recorded as $600 \mathrm{sec}^{1}$

\section{Results and Discussion}

Figure 1 gives the mean and standard error of the means for each of the four groups. The differences in the amount of suppression between the four groups proved significant when tested by a Kruskal-Wallis one-way analysis of variance, $\mathrm{H}(3)=19.38, \mathrm{p}<.05$.

The differences in suppression are in concordance with the data obtained by Lubow (1965). That is, the means of the groups suggest that the greater the number of habituation trials, the greater the attenuation of conditioning. In the latent inhibition paradigm, increased preexposure is presumed to increase habituation and, therefore, to decrease the effectiveness of the tone in conditioning, resulting in less suppression to the tone during the testing. The groups showing more suppression, then, were more effectively conditioned.

Another interesting point is clearly shown in Fig. 1. Specifically, the variance around the mean decreased with an increase in habituation trials. The almost negligible error of the mean of the groups experiencing 30 and 60 preexposure trials indicates that conditioning is almost totally ineffective after 30 trials. Examination of the individual scores of Ss in Groups 10 and 30, however, shows that these are typically either very low (around $1 \mathrm{sec}$ ) or quite high, i.e., the distribution of scores in the groups is somewhat discontinuous.

\section{EXPERIMENT II}

Thompson and Spencer (1966) concluded that one of the "parametric" characteristics of habituation was that, other things being equal, the more rapid the frequency of stimulation, the more rapid and/or more pronounced the habituation. However, Davis (1970) has demonstrated that this conclusion may be based on a confounding of training and testing trials and has shown that in habituation training, the response decrement is greater with a shorter ISI $(2 \mathrm{sec})$, but that training with a longer ISI $(16 \mathrm{sec})$ results in a greater response decrement during testing. Further, he found that the differences in testing between the two habituation training intervals diminished over a $24-\mathrm{h}$ period. The stimulus preexposure paradigm also provides differentiation between habituation training and testing, and was again used to examine the affect of ISI during habituation training on subsequent conditioning. 


\section{Method}

\section{Subjects}

The Ss were 50 male albino rats obtained from Simonson Laboratories. All Ss were between 60 and 70 days old and weighed between 280 and $300 \mathrm{~g}$ at the beginning of the experiment.

\section{Apparatus}

The experimental apparatus was the same as that used in Experiment $\mathbf{I}$.

\section{Procedure}

There were five groups of $10 \mathrm{Ss}$ each. One group received no stimulus preexposure and four groups received 10 stimulus presentations of a $60-\mathrm{dB} \quad 10-\mathrm{sec}$ tone at four different interstimulus intervals prior to conditioning. During the habituation/conditioning session, one group received the habituating tone at a 2-sec ISI (Group 2 ISI), one group received the habituating tone at a 10-sec ISI (Group 10 ISI), one at a 30 -sec ISI (Group 30 ISI), and one at 150-sec ISI (Group 150 ISI). Following the 9 tones, all groups received a 10th tone paired with shock; $8 \mathrm{sec}$ after the onset of the tone, the shock came on for $2 \mathrm{sec}$, such that the offset of the tone and the shock coincided. The fifth group served as a control and received no auditory stimulation while remaining in the chamber for $40 \mathrm{~min}$; following the $40-\mathrm{min}$ interval, a tone-shock pairing identical to that received by the other groups was given (Group C). All Ss were returned to their home cages, from which the water bottles had been removed. The testing session was conducted $24 \mathrm{~h}$ later in the same sequence employed in the previous experiment.

\section{Results and Discussion}

Figure 2 shows the mean time to completion of 10 licks after the offset of the tone for each ISI and the standard error of that mean. The figure shows an increase in response time when the ISI is decreased, i.e., conditioning was less effective with the longer interstimulus intervals. The effect proved significant when all groups were tested by a Kruskal-Wallis one-way analysis of variance, $H(4)=21.00, p<.05$. Further, no differences were found between the groups in the time taken to complete the initial 100 licks. The results, then, provide a replication of the effect found by Davis (1970), and suggest that longer interstimulus intervals during habituation training produce a greater response decrement than do shorter interstimulus intervals, when assessed under test conditions that are equivalent for all animals.

The present design does not completely control for the effect of habituation to the experimental apparatus. Specifically, each group remained in the experimental chamber for unequal amounts of time during the preexposure session; i.e., Group 2 ISI was in the chamber for $120 \mathrm{sec}$, Group 10 ISI for $200 \mathrm{sec}$, Group 30 ISI for $400 \mathrm{sec}$, Group 150 ISI for $1,600 \mathrm{sec}$, and the control group for $2,400 \mathrm{sec}$. Accordingly, for the preexposed groups, the Ss spending the least total time in the experimental chamber (shorter ISI groups) showed the most suppression. However. the control

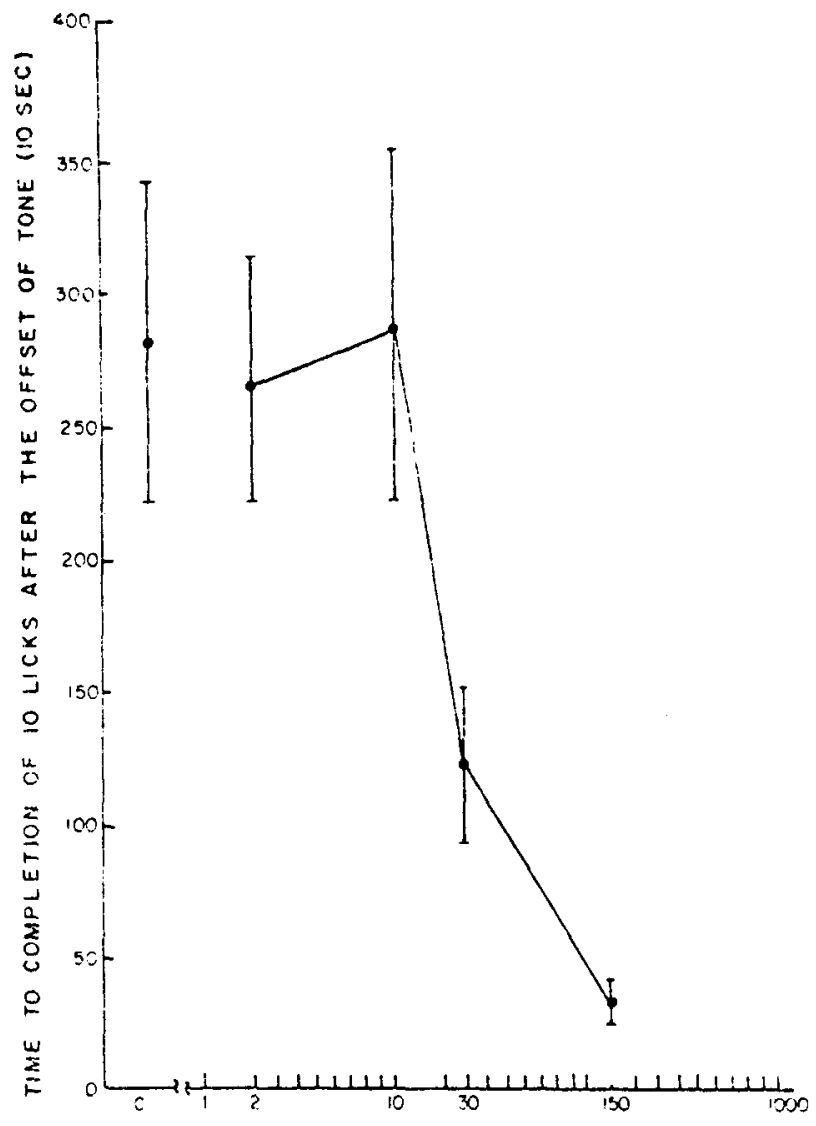

INTERSTIMULUS INTERVAL OF MABITUATING TONE (10Q SCOE)

Fig. 2. Mean time to complete 10 licks after the offset of the tone by the interstimulus interval of the tone during preexposure.

group, who showed the longest time until drinking, remained in the chamber longer than any of the preexposed groups. If time in chamber were the only relevant variable, the control group would have shown the least time to drinking.

\section{EXPERIMENT III}

Another characteristic of habituation is that the presentation of an additional stimulus produces a recovery of the habituated response. This response recovery has been termed dishabituation. Harris (1943) observed that virtually every response that may be habituated may also be dishabituated. In fact, the ability of a response to recover in the presence of additional stimulation is one of the factors which distinguishes habituation from neuronal fatigue. This experiment was conducted to examine the effect of interpolating a dishabituating stimulus between CS habituation and conditioning.

\section{Method}

\section{Subjects}

The Ss were 30 male albino rats obtained from Simonson 


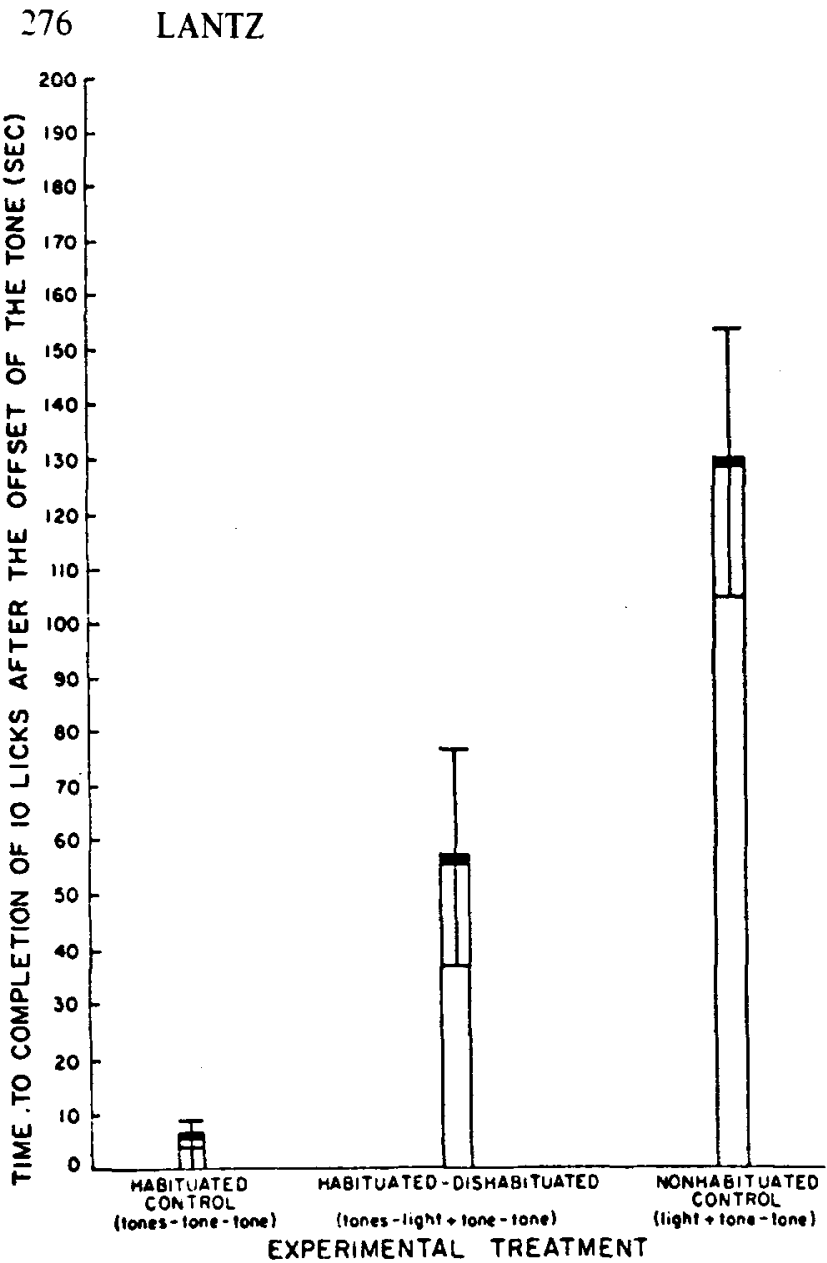

Fig. 3. Mean time to complete 10 licks after the of fset of the tone and standard error of the means of habituated, dishabituated, and control groups.

Laboratories. All Ss were between 60 and 70 days old and weighed between 280 and $300 \mathrm{~g}$ at the beginning of the experiment.

\section{Apparatus}

The apparatus was the same as that utilized in the previous experiments, except that a $7 \frac{1}{2}-\mathrm{W}$ red light was inserted $3 \mathrm{in}$. from the floor at one end of the Plexiglas chamber.

\section{Procedure}

There were three groups of $10 \mathrm{Ss}$ each. The first session, the habituation/conditioning session, was different for each of the three groups, whereas the testing session was identical for all three groups. One group, the habituated control group, received 60 presentations of the $60-\mathrm{dB} 1,000-\mathrm{Hz}$ tone for a duration of $10 \mathrm{sec}$, followed by a $30-\mathrm{sec}$ interstimulus interval. The 61 st tone was paired with shock; $8 \mathrm{sec}$ after initiation of the $61 \mathrm{st}$ tone, a 2 -sec shock came on so that the offset of the tone and the shock coincided. A second group, the dishabituated group, also received 60 presentations of the $10-\mathrm{sec} 60-\mathrm{dB}$ tone at a $30-\mathrm{sec}$ interstimulus interval during the habituation/conditioning session. Fifteen seconds prior to the 61 st tone, i.e., $15 \mathrm{sec}$ after the 60th tone, a $7 \frac{1}{2}-W$ red light mounted at one end of the chamber was iluminated. Fifteen seconds after the illumination of the red light, Ss received a tone-shock pairing identical to that received by the habituated control. A third group, the nonhabituated control group, remained in the experimental chamber in the absence of auditory stimulation for $40 \mathrm{~min}$. At the end of the $40-\mathrm{min}$ interval, the nonhabituated control received the onset of the light, tone, and shock in the same temporal sequence as the dishabituated group. The testing session, conducted $24 \mathrm{~h}$ later, was identical to that used in the previous experiments.

\section{Results and Discussion}

Figure 3 gives means and the standard error of the means for each of the three groups. The differences in the amount of suppression of the three groups seen in the figure proved to be significant when tested by a Kruskal-Wallis one-way analysis of variance, $\mathrm{H}(3)=$ $21.88, \mathrm{p}<.01$.

Examination of the figure showed almost no suppression of drinking by the habituated control group. A comparison of the habituated control group with the nonhabituated group was significant when tested by a Mann-Whitney $U(U=11, p<.05)$ and again replicates the finding of attenuated conditioning after stimulus preexposure.

The dishabituated group was significantly different from the habituated control group when tested with a Mann-Whitney $U(U=13, p<.05)$, as it was significantly different from the nonhabituated control group $(U=18, p<.05)$. This pattern of results suggests that, although the addition of another stimulus results in a recovery of the habituated response that facilitates conditioning, the recovery is not complete and the habituation trials still affect conditioning.

Thompson and Spencer (1966) pointed out that a dishabituating stimuli need not be intense to produce a response recovery, although a strong stimulus is typically used. In fact, they demonstrated that a small change in the frequency of shock was sufficient to produce a partial recovery of the response. Since a small alteration in stimulation may produce response recovery, it is possible that the additional stimulus serves an attentional function, rather than interfering with the process of habituation. Thompson and Spencer (1966) and Groves and Thompson (1970) postulated that "dishabituation" represents an independent sensitization process that may be superimposed on habituation. In the present paradigm, the sensitizing effect of the additional stimulus may represent a particularly surprising event, when presented after a long period of monotonous tones, that enhances the effect of a single conditioning trial. The dishabituating stimulus may serve, then, an attentional function that results in an increment in effectiveness of the CS.

Finally, it should be noted that any differences between the dishabituated group and the nonhabituated control group cannot be accounted for by differences in the stimuli between conditioning and testing. Although the stimulus complex was necessarily altered between the two phases, i.e., the light was not present during testing, the alteration was identical for both groups. 


\section{DISCUSSION}

These experiments indicate that those manipulations during habituation training that have been shown to produce the greatest response decrements, tested under conditions that are equivalent for all Ss, also attenuate subsequent conditioning to the greatest extent. That is, increasing the number of CS habituation trials, increasing the interstimulus interval, and omitting any interpolated stimulation serve to further attenuate conditioning.

Several recent experiments have suggested that stimulus preexposure results in an attentional decrement or a reduction in stimulus saliency (e.g., Reiss \& Wagner, 1972; Rescorla, 1971). This viewpoint, first proposed by Carlton and Vogel (1967), is certainly not disputed by any of the findings of these experiments. Since latent inhibition paradigms show a correspondence to "true" habituation paradigms, in that the same variables affect both habituation and stimulus preexposure in a similar fashion, it is suggested that future research attempt to distinguish between attentional variables and other influences in traditional habituation paradigms.

\section{REFERENCES}

Carlton, P. L., \& Vogel, J. Habituation and conditioning. Journal of Comparative \& Physiological Psychology, 1967, 63, 348-351.

Davis, M. Effects of interstimulus interval length and variability on startle-response habituation in the rat. Journal of Comparative \& Physiological Psychology, 1970, 72, 177-192.
Groves. P. M.. \& Thompson. R. F. Habituation: A dual process theory. Psychological Review, 1970, 77, 419-450.

Harris, T. D. Habituatory response decrement in the intact organism. Psychological Bulletin, 1943, 40, 385-422.

Lubow, R. E. Latent inhibition: The effect of frequency nonreinforced pre-exposure to the CS. Journal of Comparative \& Physiological Psy shology, 1959, 52, 415-419.

Lubow, R. E. \& Moore, A. U. Latent inhibition: The effect of nonreinforced pre-exposure to conditioned stimulus. Journal of Comparative \& Physiological Psychology, 1959, 52, 415-419.

Lubow, R. E., \& Siebert. L. Latent inhibition in the CER paradigm. Journal of Comparative \& Physiological Psychology, 1969. 68, 136-138.

Reiss, S., \& Wagner, A. R. CS habituation and inhibition. Learning \& Motivation, 1972, 3, 237-247.

Rescorla, R. A. Summation and retardation tests of latent inhibition. Journal of Comparative \& Physiological Psychology, 1971, 75, 77-81.

Siegel, S. Effect of CS habituation on eyelid conditioning. Journal of Comparative \& Physiological Psychology, 1969, 68. 245-248.

Thompson, R. E., \& Spencer, W. Habituation: A model phenomenon for the study of neuronal substrates of behavior. Psychological Review, 1966, 73, 16-43.

\section{NOTE}

1. Preliminary studies have shown that a much more reliable index of conditioning was obtained by measuring the number of licks after the offset of the tone. Therefore, licks made during the tone were not recorded in this study.

(Received for publication May 24, 1973; revision received July 16,1973 .) 